\title{
The Effect of Compaction Model and Temperature on Superpave Mixture Using Fiber Reinforcement
}

\author{
${ }^{1}$ Andi Alifuddin, ${ }^{2}$ Antariksa Sudikno, ${ }^{3}$ Pitojo Tri Juwono, ${ }^{4}$ Lambang Basri Said \\ ${ }^{1}$ Doctor Program of Environmental Science, Postgraduate School, Universitas Brawijaya, Indonesia \\ ${ }^{2}$ Department of Architecture Engineering, Faculty of Engineering, Universitas Brawijaya, Malang, Indonesia \\ ${ }^{3}$ Department of Irrigation and Water Resource Engineering, Faculty of Engineering, Universitas Brawijaya, Malang, Indonesia \\ ${ }^{4}$ Department of Civil Engineering, Faculty of Engineering, Indonesian Muslim University, Makassar, Indonesia
}

Correspondence Author: Andi Alifuddin, 1Universitas Brawijaya, Doctor Program of Environmental Science, Postgraduate School, , Jl. MT. Haryono 169, Malang, Indonesia, 65145,

Received date: 22 December 2017, Accepted date: 22 January 2018, Online date: 28 February 2018

Copyright: (C) 2018 Andi Alifuddin, et al. This is an open-access article distributed under the terms of the Creative Commons Attribution License, which permits unrestricted use, distribution, and reproduction in any medium, provided the original author and source are credited.

\begin{abstract}
Background: Based on the empirical characteristics and weaknesses of the mixture design procedure of Marshall Procedure, the Strategic Highway Research Program (SHRP) developed a high performance of asphalt pavement layer (SUPERPAVE) with maximum density. For the attainment of the air voids on pavement could be CS and remained within the required limits that required a maximum compacting method on the concrete mixture with absolute density approach. Objective: The objective of the study was to analyze the amount of tensile strength of the super pave mixture with fiber reinforcement by indirect tensile strength test with the density and gyratory compaction approach. Methods: Number of collisions for absolute density was $2 \times 400$ collisions and the gyratory compactor was $1.25^{\circ}$ of sloping angles. While, the variation of fibers length were $5 \mathrm{~mm}, 6 \mathrm{~mm}, 8 \mathrm{~mm}, 10 \mathrm{~mm}, 12 \mathrm{~mm}$ and $14 \mathrm{~mm}$ with temperature variation of $20^{\circ} \mathrm{C}, 30^{\circ} \mathrm{C}$, $40^{\circ} \mathrm{C}, 50^{\circ} \mathrm{C}$ and $60^{\circ} \mathrm{C}$. The tests of elastic modulus and the Poisson's ratio used indirect tensile test equipment. Results: The initial result of the Marshall mix design showed the Optimum Asphalt Content was 5.9\%.The length of the optimum fibers was $8 \mathrm{~mm}$ with the elastic modulus of $\mathrm{E}=2306735.04 \mathrm{Kpa}$; strain $(\varepsilon)=0.0134287$ for the density of $2 \times 400$ collisions and $\mathrm{E}$ $=2140563.34 \mathrm{Kpa}$ with strain $(\varepsilon)=0.0139791$, for gyratory compactors with $1.25^{\circ}$ turning angle. The superpave mixture by fiber reinforcement showed a more ductile mixture with a Possion ratio value of 0.42 compared to a Marshall mixture having a higher stiffness modulus with a Possion ratio of 0.39. Temperature decreased the elastic modulus, but the value of the Poisson ratio increased.
\end{abstract}

Key words: Refusal density, indirect tensile strength, gyratory

\section{INTRODUCTION}

Compaction may reduce air volume pore in hot asphalt mixture (HMA). The reduction of air cavities increases the unit weight or the density of the mixture, allowing the mixture to occupy a smaller void. Proper compaction of asphalt concrete mixtures is one of the important parameters needed to build stable and durable pavement structures (Amadore, A., et al., 2013; Oluwasola, E.A., et al., 2015). Non-optimal compaction generally produces a high air cavities causing unbalanced pavement structure and hence water easily penetrates into the pavement layers (Laurinavicius, A., R. Oginskas, 2006; Radziszewski, P., 2007; Mo, L., et al., 2012). Thermally modified asphalt concrete on pavement temperature is also support high performance of the HMA. Expanded polypropylene (EPP) beads and graphite powder may be used as the additives to change the thermal properties of HMA (Shi, X., et al., 2017). Lignin fibers typically used to influence the mixture performance of matrix asphalt, such as strength, stability, durability, noise level, rutting resistance, fatigue life, and water sensitivity (Sheng, Y. et al., 2017).

The absolute density (refusal density) is the greater compaction effort as a simulation of secondary compaction by traffic, until the test specimen is fixed. This product is designed based on the new mixed-system design that is called as a Supervave (superior performing asphalt pavement) mixture with the compacting approach of the absolute density method (Asi, I.M., 2007), the degree of compaction is affected by the shape, granular distribution, and texture of the aggregate surface, which affects the ease of compaction and the distribution of air voids (ASTM, 2007) which is designed based on the angle of inclination and the amount of grating and compaction of $2 \times 400$ collisions of Marshall Compaction. The Marshall Mix procedure is empirical and has limited accuracy in overall determination of the effect of different environmental conditions and loading conditions, material properties and pavement performance types (Asi, I.M., 2007). The objective of the study was to analyze the amount of tensile strength of the superpave mixture with fiber reinforcement by indirect tensile strength test with the density and gyratory compaction approach. 
Citation: Andi Alifuddin, Antariksa Sudikno, Pitojo Tri Juwono, Lambang Basri Said, 2018. The Effect of Compaction Model and Temperature on Superpave Mixture Using Fiber Reinforcement. Journal of Applied Sciences Research., 14(1): 32-39.

\section{MATERIALS AND METHODS}

The research was started with the examination and testing of the asphalt concrete mixture material including: coarse aggregate, stone dust and asphalt binder (bitumen) and asphalt concrete mix planning of Asphalt Concrete Wearing Course (AC-WC) based on asphalt content of the plan (s) with variation of five asphalt content $(-1,-0.5, \mathrm{~s}(\%),+0.5,+1)$ to determine the mix characteristics and determination of optimum asphalt content. Then, the mixture planning was based on the variation of length and percentage of fiber based on the optimum bitumen content to determine the length and percentage of the optimum fibers in the design of the mixture for absolute density with VIM refusal $_{\text {of }} 6 \%$ and the superpave mixture of VIM $4 \%$.

Temperature testing design of the specimens test was at temperature variations of $20^{\circ} \mathrm{C}, 30^{\circ} \mathrm{C}, 40^{\circ} \mathrm{C}, 50^{\circ} \mathrm{C}$ and $60^{\circ} \mathrm{C}$. These temperatures represent the pavement temperature in Indonesia during the daytime hours. Temperature of $60^{\circ} \mathrm{C}$ is a representation of the temperature of the pavement at the midday while the temperature of $30 \mathrm{oC}$ is the representation of the temperature of the pavement in the morning and evening. Temperature of $20^{\circ} \mathrm{C}$ represents the room temperature, while $40^{\circ} \mathrm{C}$ and $50^{\circ} \mathrm{C}$ was the represented temperature between morning and afternoon and afternoon and evening.

The specimens for Marshall test were treated with indirect tensile strength (ITS) with size of 98.85 x 65.5 mm with compacting model of 2 x 75 collisions, 2 $\mathrm{x} 400$ collision and gyratory compressor with turning angle of $1.25^{\circ}$ Marshall and indirect tensile strength test was used to determine the mix and modulus stability characteristics of the modified asphalt mixture of fiber with an absolute density of $2 \times 400$ collisions and the gyratory compactor as the implementation of mix density on the field conditions. Tests were conducted on the variation of length and the percentage of fibers to measure the degree of ductility and elastic modulus of the mixture to temperature variations and the percentage of density produced.

\section{RESULTS AND DISCUSSION}

This study showed that all coarse aggregate and stone dust characteristics comply with Indonesian Standard (Table 1).

Table 1: The results of coarse aggregate characteristic testing and stone dust

\begin{tabular}{|c|c|c|c|c|c|}
\hline No. & Testing & Method & Requirement & Result & Description* \\
\hline \multicolumn{6}{|c|}{ Coarse aggregate } \\
\hline 1. & Water absorption & SNI 03-1969-1990 & $\leq 3 \%$ & 2.194 & $\mathrm{CS}$ \\
\hline 2. & Bulk density & SNI 03-1969-1990 & $\geq 2.50 \mathrm{gr} / \mathrm{cc}$ & 2.515 & $\mathrm{CS}$ \\
\hline 3. & Apparent specific gravity & SNI 03-1969-1990 & - & 2.672 & $\mathrm{CS}$ \\
\hline 4. & Effective density & SNI 03-1969-1990 & - & 2.588 & $\mathrm{CS}$ \\
\hline 5. & Stickiness of the asphalt & SNI 03-2439-1991 & $\geq 95 \%$ & 98 & $\mathrm{CS}$ \\
\hline 6. & Abrasion test & SNI 03-2439-1991 & Max. $40 \%$ & 24.40 & $\mathrm{CS}$ \\
\hline 7. & Soundness test & SNI 03-2439-1991 & $\leq 7 \%$ & 1.35 & $\mathrm{CS}$ \\
\hline 8. & Flat and oval particles & ASTM D-4791** & Max. $25 \%$ & 14.3 & $\mathrm{CS}$ \\
\hline \multicolumn{6}{|c|}{ Stone dust aggregate } \\
\hline 1. & Water absorption & SNI 03-1970-1990 & $\leq 3 \%$ & 2.461 & $\mathrm{CS}$ \\
\hline 2. & Bulk density & SNI 03-1970-1990 & $\geq 2.50 \mathrm{gr} / \mathrm{cc}$ & 2.622 & $\mathrm{CS}$ \\
\hline 3. & Apparent specific gravity & SNI 03-1970-1990 & - & 2.559 & CS \\
\hline 4. & Effective density & SNI 03-1970-1990 & - & 2.572 & $\mathrm{CS}$ \\
\hline 5. & Soundness test & SNI 03-2439-1990 & $\leq 5 \%$ & 3.115 & $\mathrm{CS}$ \\
\hline 6. & Sand Equivalent & AASTHO-T-176 & $\geq 50 \%$ & 71.12 & $\mathrm{CS}$ \\
\hline
\end{tabular}

Note * CS = comply with standard; **[10]

Test results of asphalt properties of the pen 60/70 Pertamina Co. Ltd. were met with Indonesian standard (Table 2)

Table 2: Test results of asphalt properties of the pen 60/70 Pertamina Co. Ltd.

\begin{tabular}{|c|c|c|c|c|c|c|}
\hline \multirow{2}{*}{ No. } & \multirow{2}{*}{ Properties } & \multirow{2}{*}{ Unit } & \multirow{2}{*}{ Method } & \multicolumn{2}{|c|}{ Pen $60 / 70$} & \multirow{2}{*}{ Description* } \\
\hline & & & & Min & Max & \\
\hline 1. & Penetration $\left(25^{\circ} \mathrm{C}, 100 \mathrm{gr}, 5\right.$ second $)$ & $0.1 \mathrm{~mm}$ & SNI 06-2456-1991 & 60 & 79 & $\mathrm{CS}$ \\
\hline 2. & Softening Point Test (ring and ball test) & ${ }^{\circ} \mathrm{C}$ & SNI 06-2434-1991 & 48 & 58 & CS \\
\hline 3. & Flash Point Test (Cleveland open cup) & ${ }^{\circ} \mathrm{C}$ & SNI 06-2433-1991 & 200 & - & $\mathrm{CS}$ \\
\hline 4. & Solubility $\left(\mathrm{CCl}_{4}\right)$ & $\%$ & ASTM-D-2042 & 99 & - & $\mathrm{CS}$ \\
\hline 5. & Specific gravity $\left(25^{\circ} \mathrm{C}\right)$ & $\mathrm{Gr} / \mathrm{cm}^{3}$ & SNI 06-2488-1991 & 1 & - & $\mathrm{CS}$ \\
\hline 6. & Ductility $\left(25^{\circ} \mathrm{C}, 5 \mathrm{~cm}\right.$ per minute $)$ & $\mathrm{Cm}$ & SNI 06-2432-1991 & 100 & - & $\mathrm{CS}$ \\
\hline
\end{tabular}

Note $*$ CS = comply with standard

Based on the Marshall test, results met the parameters and specifications of the mixture with minimum asphalt content range of 5.5\% and a maximum of $6.3 \%$ (Table 3$)$. The amount of optimum bitumen content $(\mathrm{KAO})$ was based on the mean value of the asphalt rate range was $(5.5 \%+6.3 \%): 2=5.9 \%$.

Table 3: Mix properties of Marshall test results

\begin{tabular}{|c|c|c|c|c|c|c|c|}
\hline \multirow{2}{*}{$\begin{array}{l}\text { Marshall } \\
\text { Parameters }\end{array}$} & \multirow{2}{*}{ Unit } & \multicolumn{5}{|c|}{ Asphalt content } & \multirow[b]{2}{*}{ Spec. } \\
\hline & & 5 & 5.5 & 6 & 6.5 & 7 & \\
\hline Density & $\mathrm{gr} / \mathrm{cm}^{3}$ & 2.207 & 2.253 & 2.293 & 2.328 & 2.351 & - \\
\hline Stability & $\mathrm{Kg} / \mathrm{cm}^{2}$ & 1298.94 & 1358.40 & 1390.65 & 1366.46 & 1330.18 & $>800 \mathrm{~kg}$ \\
\hline Flow & $\mathrm{mm}$ & 3.50 & 3.53 & 3.57 & 3.60 & 3.77 & $2-4$ \\
\hline VIM & $\%$ & 7.60 & 6.54 & 4.90 & 3.45 & 3.45 & $3-5$ \\
\hline VMA & $\%$ & 17.85 & 16.91 & 15.44 & 14.16 & 13.93 & Min. 15 \\
\hline VFB & $\%$ & 57.46 & 61.30 & 68.31 & 75.65 & 77.08 & Min. 65 \\
\hline MQ & $\mathrm{kg} / \mathrm{mm}$ & 371.17 & 384.66 & 390.4 & 379.9 & 353.6 & Min. 250 \\
\hline
\end{tabular}

Figure 1 showed that the increasing of asphalt content could increase the stability of asphalt concrete mixture, this indicated that the mixture has increased the density. This was caused by the increasing of asphalt content made the void in the mixture could still be filled by the asphalt, so that the mixture becomes denser, but it was inversely proportional to the value of the void in minerals aggregate (VMA). In the other hand, VIM value decreased with asphalt content (Figure 2). It seemed that the increasing of asphalt content made VMA values smaller (Figure 3), this was because there were more cavities filled by asphalt. In contrast, the increase of VMA values indicates that the amount of asphalt entering the void was still requiring. The expected value of VMA in the asphalt concrete mixture was as minimum as possible, in order to make the asphalt adhere to the aggregate. 


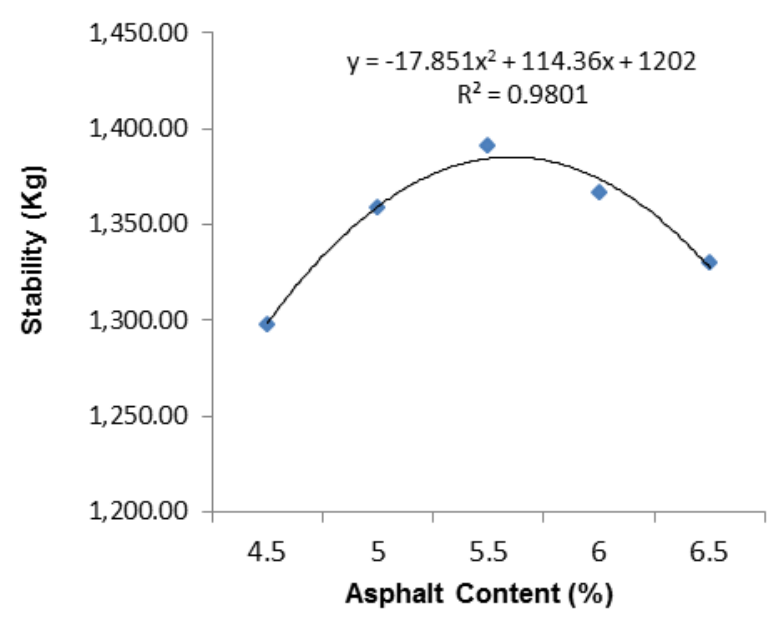

Fig. 1: Correlation of stability and asphalt content

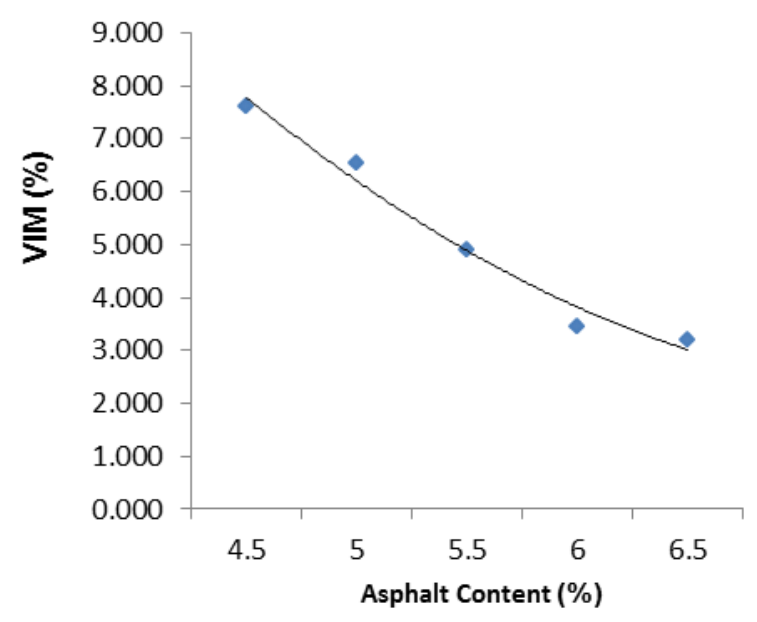

Fig. 2: Correlation of VIM and asphalt content

Figure 4 showed that as the asphalt content increased, the value of the void filled with asphalt (VFA) would increase. This was because of the voids in the mixture shrink due to the increasing levels of permeate asphalt, and then covered the aggregate particles. A low VFA value means there were only a modicum of the effective asphalt that filled the voids among the aggregate particles, so that the air void was large. This will reduce the durability of the mixture. Otherwise, if the VFA value was too high, it would cause bleeding because the voids between the granular particles were too small. VFA value is a part of VMA filled with effective asphalt, in which its value will increase if the asphalt content increased due to the increasing amount of asphalt which filled VMA.

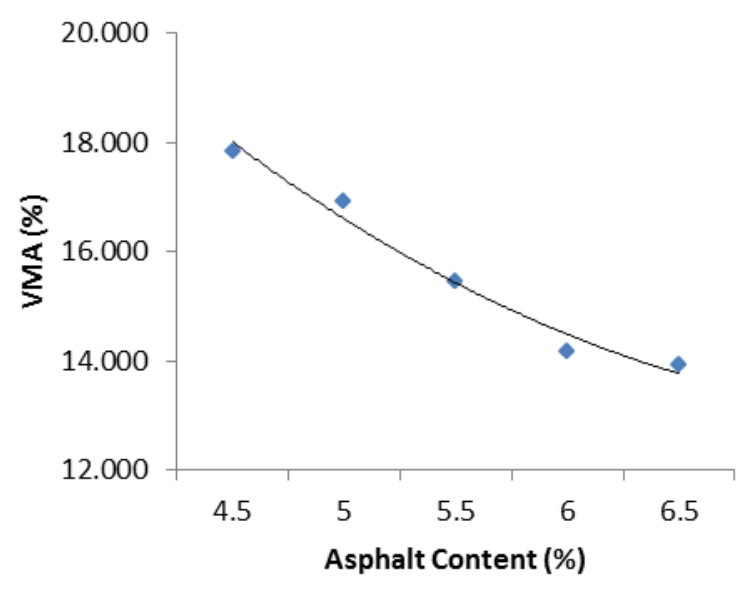

Fig. 3: Correlation of VMA and asphalt content 
Citation: Andi Alifuddin, Antariksa Sudikno, Pitojo Tri Juwono, Lambang Basri Said, 2018. The Effect of Compaction Model and Temperature on Superpave Mixture Using Fiber Reinforcement. Journal of Applied Sciences Research., 14(1): 32-39.

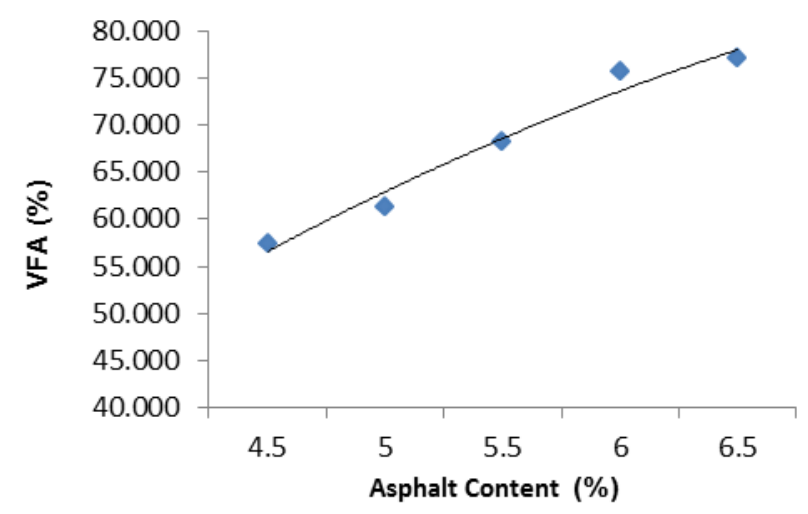

Fig. 4: Correlation of VFB and asphalt content

Flow is the magnitude of the specimen mixture due to a load to the limit of collapse in the unit of mm. Flow is an indicator of the flexibility of hot asphalt mixture in holding the traffic load. The flow value represented the deformation of the substance of the specimen, a mixture having a low flow rate with high stability would tend to produce a rigid and brittle hot asphalt mixture, which would easily crack if exposed to high and heavy traffic loads. Conversely, High flow values indicate an asphalt mixture that has plastic behavior, so it was easily changed shape (plastic deformation) due to high and heavy traffic load.

Marshall Quotient (MQ) is the division result of stability and flow that indicates an approach to the stiffness and flexibility of hot asphalt mixture (Figure 5). The magnitude of the MQ depends on the magnitude of the stability value affected by the friction among the granular particles (fictional resistance) and interlocking of the aggregate particles and the cohesion of the mixture, and the value of the flow influenced by the viscosity, asphalt, gradation of stacking materials and number of collisions.

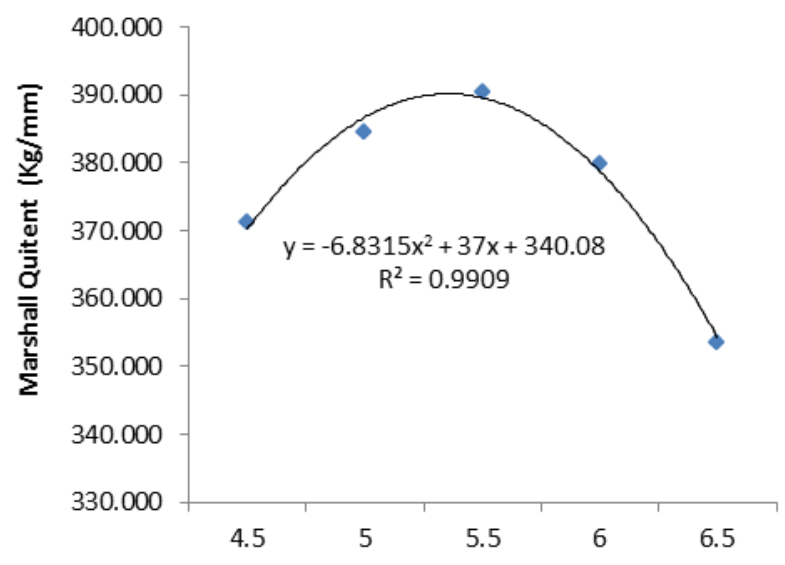

Fig. 5: Correlation of MQ and asphalt content

Asphalt concrete mixture that had low MQ values led to the hot asphalt mixture that was more flexible and tend to be plastic, so it is easy to change shape when receiving high traffic load. While the mixture that had a high MQ led to the hot asphalt mixture that was stiff and less flexible. Factors influencing MQ value were the gradation of flats, grain shape, asphalt content, cohesion, compaction energy, and compaction temperature. The decrease of MQ value was due to the thickness of the asphalt film covering the aggregate surface that was too thick and some of the asphalt rose on the surface, so that both the stability and the MQ would decrease.

The result of indirect tensile strength testing as in the Table 4 with variation of fiber lengths showed that Marshall mix design with the compaction of $2 \times 400$ collisions had higher elastic modulus value with lower strain compared to Superpave mix design with gyratory compressor and turning angle of $1.25^{\circ}$. This result indicated that the Marshall mix design had higher stiffness properties than the Superpave mix design that was more flexible. The effect of the compacting model with an absolute density of $2 \times 400$ collisions gave a higher mixed density with smaller void content to a minimum limitation of $3.394 \%$, compared to the Superpave mixture that the gyratory compaction producing the air-void of $4.130 \%$ in which it was still in ratio mix design under VIM conditions of $4 \%$. The gyratory compacting system model is an application of the compaction method in the field so that the potential for the decrease of air void due to the traffic load on the planned VIM ratio was constant. Some factors that can affect the compaction level were: air temps, layer thickness, maximum aggregate size, humidity, and solar radiation (Dubois, V., et al., 2010; Khan, Z.A., et al., 1998; Airey, G.D., et al., 2008; Hainin, M.R., et al., 2013; Ahmad, J., et al., 2014).

Table 4: Indirect Tensile Strength Test Result with the

\begin{tabular}{|c|c|c|c|c|c|c|c|c|}
\hline Compaction & Mix & \multirow{2}{*}{ Unit } & \multicolumn{6}{|l|}{ Fiber Length } \\
\hline Type & Properties & & $5 \mathrm{~mm}$ & $6 \mathrm{~mm}$ & $8 \mathrm{~mm}$ & $10 \mathrm{~mm}$ & $12 \mathrm{~mm}$ & $14 \mathrm{~mm}$ \\
\hline \multicolumn{9}{|l|}{ Marshall (M-F) } \\
\hline \multirow{6}{*}{$2 \times 400$} & ITS & Kpa & 25051.15 & 27947.9964 & 30976.519 & 27256.70 & 22187.22 & 14517.157 \\
\hline & Possiom Ratio & - & 0.28 & 0.32 & 0.33 & 0.30 & 0.28 & 0.25 \\
\hline & $\begin{array}{ll}\begin{array}{l}\text { Vertical } \\
\text { (VS) }\end{array} & \text { Def. } \\
\end{array}$ & $\mathrm{mm}$ & 3.22 & 3.22 & 3.27 & 3.19 & 3.12 & 3.05 \\
\hline & $\begin{array}{l}\begin{array}{l}\text { Horizontal Def. } \\
\text { (HS) }\end{array} \\
\end{array}$ & $\mathrm{mm}$ & 0.92 & 1.03 & 1.08 & 0.98 & 0.90 & 0.80 \\
\hline & Strain & $\mathrm{mm}$ & 0.01008989 & 0.01137406 & 0.01192442 & 0.0108237 & 0.0099064 & 0.0088057 \\
\hline & Elastic Modulus & Kpa & 2482796.58 & 2457169.82 & 2597738.54 & 2518242.19 & 2239676.58 & 1648604.66 \\
\hline \multicolumn{9}{|l|}{ Superpave (S-F) } \\
\hline \multirow{3}{*}{ Gyratory, $1.25^{0}$} & ITS & Kpa & 21726.36 & 26795.84 & 29923.1199 & 26137.467 & 20738.796 & 15307.21 \\
\hline & Possiom Ratio & - & 0.33 & 0.34 & 0.37 & 0.35 & 0.28 & 0.29 \\
\hline & $\begin{array}{l}\text { Vertical } \\
\text { (VS) }\end{array}$ & $\mathrm{mm}$ & 3.02 & 3.18 & 3.23 & 3.18 & 3.08 & 3.10 \\
\hline
\end{tabular}


Citation: Andi Alifuddin, Antariksa Sudikno, Pitojo Tri Juwono, Lambang Basri Said, 2018. The Effect of Compaction Model and Temperature on Superpave Mixture Using Fiber Reinforcement. Journal of Applied Sciences Research., 14(1): 32-39.

\begin{tabular}{|l|l|l|l|l|l|l|l|l|}
\hline & $\begin{array}{l}\text { Horizontal Def. } \\
\text { (HS) }\end{array}$ & $\mathrm{mm}$ & 0.97 & 1.02 & 1.08 & 1.03 & 0.93 & 0.85 \\
\cline { 2 - 9 } & Strain & $\mathrm{mm}$ & 0.01064025 & 0.01119061 & 0.01192442 & 0.0113741 & 0.0102733 & 0.0093561 \\
\cline { 2 - 9 } & Elastic Modulus & $\mathrm{Kpa}$ & 2041903.03 & 2394493.93 & 2509398.87 & 2297989.20 & 2018699.58 & 1636070.25 \\
\hline
\end{tabular}

Furthermore, in Table 5 and Table 6 the results of mixed tests with and without fiber over temperature variations showed that the non-fiber-fiber mixture as in Figure 9 with the same compaction model has a higher ITS value than the mixture with fiber strengthening of all fiber variation testing.

Table 5: Indirect tensile strength test results with the variation of temperature (without fiber)

\begin{tabular}{|c|c|c|c|c|c|c|c|}
\hline Compaction & Mix & \multirow{2}{*}{ Unit } & \multicolumn{5}{|c|}{ Temperature Testing } \\
\hline Type & Ptoperties & & $20^{\circ} \mathrm{C}$ & $30^{\circ} \mathrm{C}$ & $40^{\circ} \mathrm{C}$ & $50^{\circ} \mathrm{C}$ & $60^{\circ} \mathrm{C}$ \\
\hline \multicolumn{8}{|c|}{ Marshall (M-WF) Without Fiber } \\
\hline \multirow{6}{*}{$2 \times 75$} & ITS & Kpa & $36,046.00$ & $25,182.82$ & $16,196.01$ & $10,073.13$ & $6,847.76$ \\
\hline & Possion Ratio & - & 0.13 & 0.15 & 0.18 & 0.23 & 0.28 \\
\hline & Vertical Def. (VS) & $\mathrm{mm}$ & 2.65 & 2.80 & 3.02 & 3.12 & 3.20 \\
\hline & Horizontal Def. (HS) & $\mathrm{mm}$ & 0.28 & 0.31 & 0.46 & 0.59 & 0.86 \\
\hline & Strain & $\mathrm{mm}$ & 0.00 & 0.00 & 0.01 & 0.01 & 0.01 \\
\hline & Elastic Modulus & Kpa & $11,695,639.64$ & $8,170,925.70$ & $5,255,026.82$ & $3,268,370.93$ & $2,221,853.56$ \\
\hline \multicolumn{8}{|c|}{ Marshall (M-WF) Without Fiber } \\
\hline \multirow{6}{*}{$2 \times 400$} & ITS & Kpa & $67,713.81$ & $51,188.62$ & $34,860.93$ & $21,199.66$ & $8,986.81$ \\
\hline & Possion Ratio & - & 0.13 & 0.18 & 0.22 & 0.27 & 0.36 \\
\hline & Vertical Def. (VS) & $\mathrm{mm}$ & 2.82 & 3.12 & 3.15 & 3.17 & 3.24 \\
\hline & Horizontal Def. (HS) & $\mathrm{mm}$ & 0.38 & 0.50 & 0.62 & 0.77 & 1.03 \\
\hline & Strain & $\mathrm{mm}$ & 0.004219409 & 0.00550358 & 0.00678775 & 0.0085122 & 0.01137406 \\
\hline & Elastic Modulus & Kpa & 21970714.52 & 16608877.53 & 11311126.24 & 6878531.92 & 2915899.40 \\
\hline \multicolumn{8}{|c|}{ Superpave (M-WF) Without Fiber } \\
\hline \multirow{6}{*}{ Gyratory } & ITS & Kpa & $52,342.86$ & $39,508.69$ & 26813.04 & 14129.015 & $5,218.66$ \\
\hline & Possion Ratio & - & 0.17 & 0.20 & 0.24 & 0.31 & 0.40 \\
\hline & Vertical Def. (VS) & $\mathrm{mm}$ & 2.85 & 3.00 & 3.11 & 3.27 & 3.28 \\
\hline & Horizontal Def. (HS) & $\mathrm{mm}$ & 0.31 & 0.34 & 0.52 & 0.68 & 0.97 \\
\hline & Strain & $\mathrm{mm}$ & 0.003412218 & 0.00374243 & 0.00572372 & 0.00748487 & 0.01067694 \\
\hline & Elastic Modulus & Kpa & 16983388.68 & 12819158.88 & 8699873.87 & 4584360.76 & 1693268.79 \\
\hline
\end{tabular}

Table 6: Indirect tensile strength test results with the variations of temperature (with fiber)

\begin{tabular}{|c|c|c|c|c|c|c|c|}
\hline \multirow{2}{*}{$\begin{array}{l}\text { Compaction } \\
\text { Type }\end{array}$} & \multirow{2}{*}{$\begin{array}{l}\text { Mix } \\
\text { Properties }\end{array}$} & \multirow{2}{*}{ Unit } & \multicolumn{5}{|c|}{ Temperature Testing } \\
\hline & & & $20^{\circ} \mathrm{C}$ & $30^{\circ} \mathrm{C}$ & $40^{\circ} \mathrm{C}$ & $50^{\circ} \mathrm{C}$ & $60^{\circ} \mathrm{C}$ \\
\hline \multicolumn{8}{|c|}{ Marshall (M-F) With Fiber } \\
\hline \multirow{6}{*}{$2 \times 75$} & ITS & Kpa & $32,787.05$ & $21,397.17$ & $17,113.46$ & $7,472.55$ & $1,316.75$ \\
\hline & Possion Ratio & - & 0.14 & 0.14 & 0.21 & 0.25 & 0.29 \\
\hline & $\begin{array}{l}\text { Vertical Def. } \\
\text { (VS) }\end{array}$ & $\mathrm{mm}$ & 2.88 & 2.98 & 3.02 & 3.12 & 3.08 \\
\hline & $\begin{array}{l}\begin{array}{l}\text { Horizontal Def. } \\
(\mathrm{HS})\end{array} \\
\end{array}$ & $\mathrm{mm}$ & 0.40 & 0.41 & 0.60 & 0.72 & 0.83 \\
\hline & Strain & $\mathrm{mm}$ & 0.004402862 & 0.00447624 & 0.00660429 & 0.00788846 & 0.00917263 \\
\hline & Elastic Modulus & Kpa & 10638226.38 & 6942617.62 & 5552705.19 & 2424575.69 & 427238.01 \\
\hline \multicolumn{8}{|c|}{ Marshall (M-F) With Fiber } \\
\hline \multirow{6}{*}{$2 \times 400$} & ITS & Kра & $59,648.73$ & 44440.277 & 30910.6816 & 19685.40 & 8460.112 \\
\hline & Possion Ratio & - & 0.15 & 0.19 & 0.23 & 0.30 & 0.39 \\
\hline & $\begin{array}{l}\text { Vertical Def. } \\
\text { (VS) }\end{array}$ & $\mathrm{mm}$ & 2.75 & 3.05 & 3.20 & 3.22 & 3.32 \\
\hline & $\begin{array}{l}\text { Horizontal Def. } \\
\text { (HS) }\end{array}$ & $\mathrm{mm}$ & 0.42 & 0.55 & 0.67 & 0.85 & 1.12 \\
\hline & Strain & $\mathrm{mm}$ & 0.004586314 & 0.00605394 & 0.0073381 & 0.00935608 & 0.01229132 \\
\hline & Elastic Modulus & Kpa & 19353881.73 & 14419282.74 & 10029412.22 & 6387208.21 & 2745004.20 \\
\hline \multicolumn{8}{|c|}{ Superpave (S-TSI) Control } \\
\hline \multirow{6}{*}{ Gyratory } & ITS & Kpa & $48,094.26$ & $36,046.00$ & 23339.3751 & 12015.3342 & $4,246.52$ \\
\hline & Possion Ratio & - & 0.18 & 0.22 & 0.26 & 0.32 & 0.41 \\
\hline & $\begin{array}{ll}\begin{array}{l}\text { Vertical } \\
\text { (VS) }\end{array} & \text { Def. } \\
\end{array}$ & $\mathrm{mm}$ & 2.92 & 3.08 & 3.23 & 3.27 & 3.37 \\
\hline & $\begin{array}{l}\begin{array}{l}\text { Horizontal Def. } \\
(\mathrm{HS})\end{array} \\
\end{array}$ & $\mathrm{mm}$ & 0.52 & 0.62 & 0.73 & 0.92 & 1.18 \\
\hline & Strain & $\mathrm{mm}$ & 0.00568703 & 0.00678775 & 0.00807191 & 0.01008989 & 0.01298844 \\
\hline & Elastic Modulus & Kра & 15604868.21 & 11695640.45 & 7572793.68 & 3898546.82 & 1377842.57 \\
\hline
\end{tabular}

Furthermore, the results of indirect tensile strength test as shown in Table 4 indicate that the optimum fiber length of the compaction model with the elastic modulus and maximum strain was obtained the same result but different compaction model on the fibers with fiber length of 8 mm (Figure 6). Fibers with the length of $8 \mathrm{~mm}$ were the ideal length that provided the balance among the ratio of lengths to layer thickness which gave a more flexible mixture.

The effect of the fiber length factor was the fibers with shorter sizes having more flexible properties and lower stiffness modulus than the fibers with the length of $>8 \mathrm{~mm}$ with higher elastic modulus (Figure 8). The stiffness indication of a mixture was a change in the shape of a smaller specimen after loading and vice versa, if it shows the larger shape change and returns after loading, it indicates that it has plastic deformation properties or the mixture is flexible. 


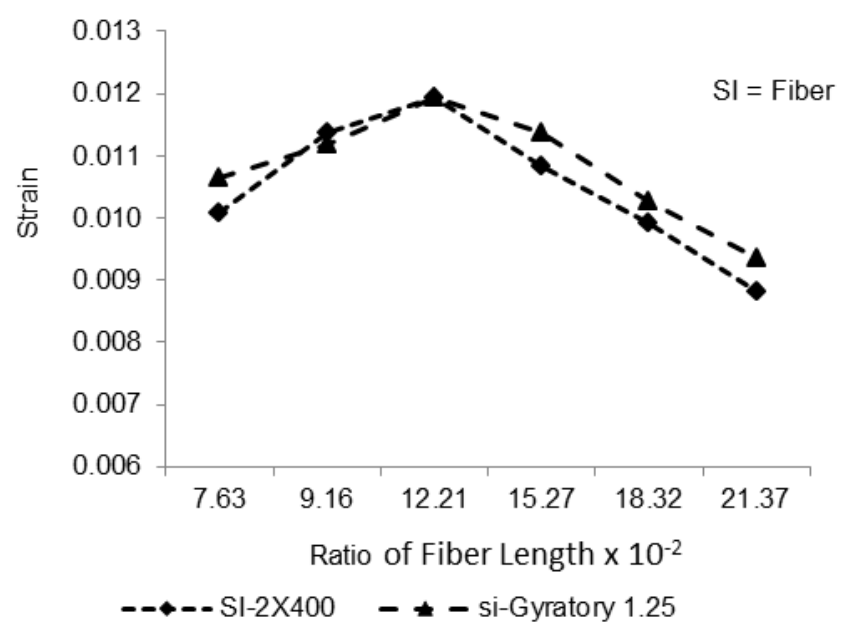

Fig. 6: The correlation of strain and the ratio of fiber length

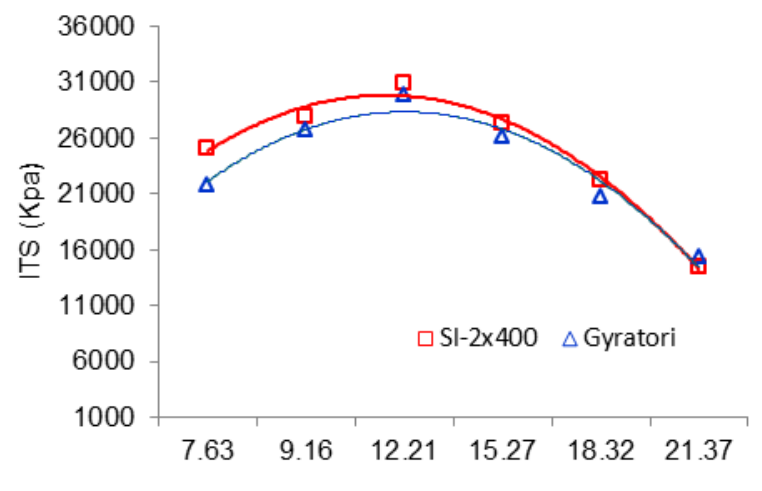

The ratio of fiber length $\times 10^{-2}$

Fig. 7: Correlation of ITS and fiber length ratio

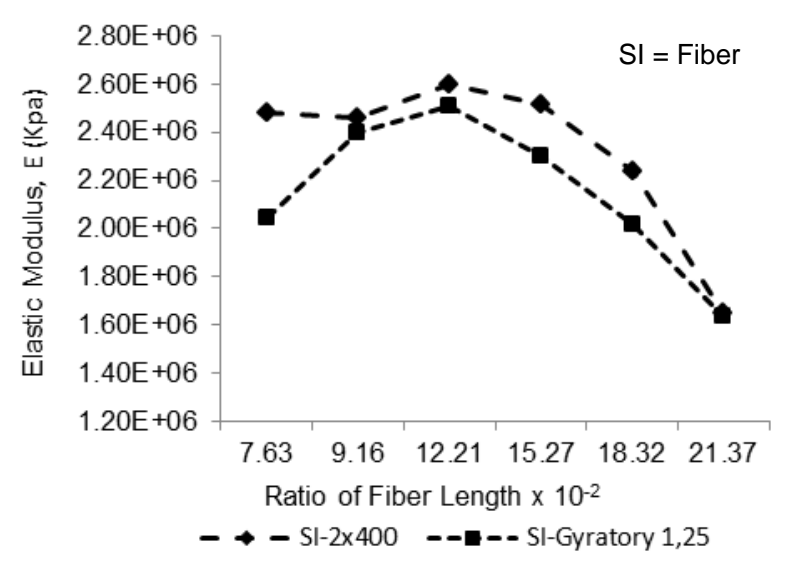

Fig. 8: The correlation of elastic modulus and the ratio of fiber length

Figure 7 showed the value of the ITS increased with the length ratio, and peaked at the optimum length of $8 \mathrm{~mm}$ (with ratio 12.21 x 10-2). Then, the ITS value decreased and it is directly proportional to the strain value in Figure 6. The compaction with an absolute density of $2 \mathrm{x} 400$ collisions has greater tensile strength compared to gyratory compactors. The ratio of fiber length meant the ratio between fiber length and fiber with layer thickness (thickness of specimen).

The test results show that the longer-sized fibers had a lower density in the mixture than the shorter ones and prone to damage and fracture during the process of mixing and compaction. This condition indicates that there was an increase in voids in the mixture (García, A., et al., 2013). The bonding increase between the surface area of the fiber and the mixture brought an effect on the increasing the tensile strength of the mixture and preventing the failure of the mixture to crack and rutting (Yoo, P.J., K.H. Kim, 2014). Figure 10 showed a mixture of 2 x 400 compaction using either fiber or without using fibers of elastic modulus value higher than the mixture with gyratory compactors with the strain value occurring in Fig. 12 smaller than that of the gyratory compressor. This suggests that mixtures with gyratory compactors exhibit more flexible properties and characteristic mixtures with smaller stiffness module bathed in mixtures with compacting 2 x 400 impacts. 
Citation: Andi Alifuddin, Antariksa Sudikno, Pitojo Tri Juwono, Lambang Basri Said, 2018. The Effect of Compaction Model and Temperature on Superpave Mixture Using Fiber Reinforcement. Journal of Applied Sciences Research., 14(1): 32-39.

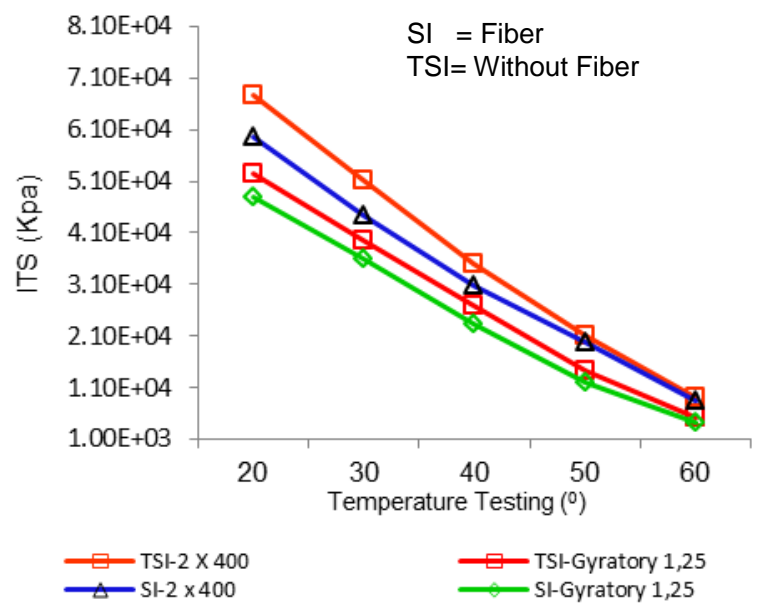

Fig. 9: The correlation of ITS and temperature in the mixture with and without fiber

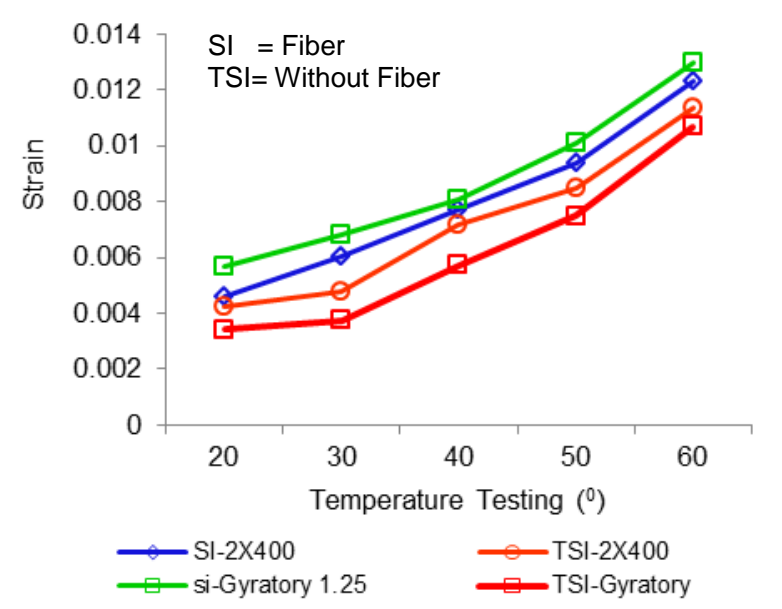

Fig. 11: The correlation of stress and temperature in the mixture with and without fiber

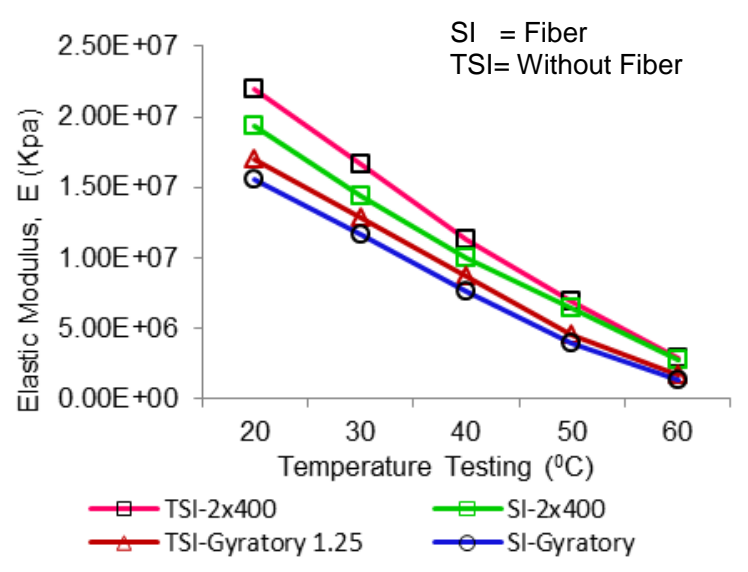

Fig. 10: The correlation of elastic modulus and the temperature in the mixture with and without the fiber

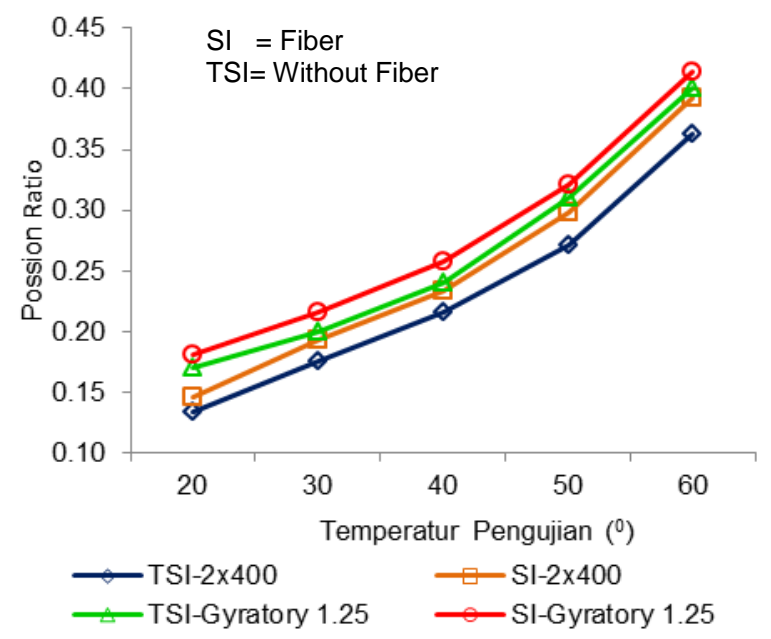

Fig. 12: The correlation of Poisson ratio and temperature in the mixture with and without fiber

The influence of the density level results in a change in the horizontal deformation due to the influence of the smaller temperature so that the stiffness modulus becomes larger as shown in Figure 11 where the Possion ratio in the mixture with the temperature variation shows that the higher the temperature from $20^{\circ} \mathrm{C}$ to $60^{\circ} \mathrm{C}$ the Possion ratio value is greater than 0.13 to 0.36 for a mixture of non-fiber fibers and mixtures with fibers of 0.15 to 0.39 fibers with a compaction of $2 \times 400$ collisions. As for the superpave gyratory composite angle of rotation $1.25^{\circ}$ without fiber increase in Possion ratio from 0.17 to 0.40 and the mixture with fibers increase the Possion ratio of 0.18 to 0.41 . The maximum Possion ratio value occurred at optimum fiber length of 8 mm with $0.6 \%$ fiber content percentage of 0.39 for Marshall and 0.42 for superpave mixture. The degree of density affects the increase in the stiffness modulus of the mixture to temperature. The result of the Poisson ratio test on the mixture with the temperature variation as shown in Figure 12 that shows the higher temperature from $20^{\circ} \mathrm{C}$ to $60^{\circ} \mathrm{C}$ the higher the Possion ratio value from 0.13 to 0.36 of the mixture without fibers, while the mixture with the fibers was 0.15 to 0.39 with the compaction of 2 x 400 collisions. While, the Superpave gyratory compressors with the turning angle of $1.25^{\circ}$ without fiber increased in passion ratio from 0.17 to 0.40 and the mixture with fibers increased in the ratio of the passion ratio of 0.18 to 0.41 , these results indicate that with the increasing of temperature in the horizontal strain (horizontal deformation) and vertical strain (Vertical deformation) occurring due to the greater loading so that the mixture becomes flexible and flexible with increased passion ratio. The attainment of more efficient density highly depended on an efficient compaction model in reducing the void volume in the mixture to achieve the desired density (Huang, L.S., et al., 2012; Oluwasola, E.A., et al., 2015; Jiménez., F.P. et al., 2014). Passion ratio is the ratio between vertical deformation with horizontal deformation and the value of this passion ratio is one indicator of the modulus stiffness rate of a mixture.

\section{Conclusion:}

The initial result of the Marshall mix design showed the Optimum Asphalt Content was 5.9\%. The length of the optimum fibers was 8 mm with the elastic modulus of $E=2306735.04 \mathrm{Kpa}$; strain $(E)=0.0134287$ for the density of $2 \times 400$ collisions and $E=2140563.34 \mathrm{Kpa}$ with strain $(\mathcal{E})=0.0139791$, for gyratory compactors with $1.25^{\circ}$ turning angle. The superpave mixture by fiber reinforcement showed a more ductile mixture with a Possion ratio value of 0.42 compared to a Marshall mixture having a higher stiffness modulus with a Possion ratio of 0.39 . Temperature decreased the elastic modulus but the value of the poisson ratio increased.

The superpave mix with fast compactors exhibits a more flexible mixture of properties using non-fiber fibers or fibers compared to the Marshall mix design with a density of $2 \times 400$ collisions. This shows that the mixture with absolute density has a mixed density with air void volume at the minimum required, so the degree of flexibility and shape change occurring in the specimen is smaller than that of the supervave mix design with the strain-gyratory loader, which is more interdependent with the deformation horizontal and vertical deformation. Thus, in a field application for road construction, the superpave mixture with Optimum Asphalt Content was $5.9 \%$ and the $8 \mathrm{~mm}$ blend of fiber is the best mixture.

\section{REFERENCES}

Amadore, A., G. Bosurgi, O. Pellegrino, 2013. Analysis of Hot Mix Asphalt Compaction Data by Means of Fuzzy Clustering Techniques Construction and Building Materials, 40: 430-437. 
Citation: Andi Alifuddin, Antariksa Sudikno, Pitojo Tri Juwono, Lambang Basri Said, 2018. The Effect of Compaction Model and Temperature on Superpave Mixture Using Fiber Reinforcement. Journal of Applied Sciences Research., 14(1): 32-39.

Oluwasola, E.A., M.R. Hainin, M.M.A. Aziz, 2015. Evaluation of Asphalt Mixtures Incorporating Electric Arc Furnace Steel Slag and Copper Mine Tailings for Road Construction. Transp. Geotech, 2: 47-55.

Laurinavicius, A., R. Oginskas, 2006. Experimental Research on The Development of Rutting in Asphalt Concrete Pavements Reinforced with Geosynthetic Materials. Civ. Eng. Manage, 12(4): 311-317.

Radziszewski, P., 2007. Modified Asphalt Mixtures Resistance to Permanent Deformations. Civ. Eng. Manage, 13(4): $307-315$.

Mo, L., X. Li, X. Fang, M. Huurman, S. Wu, 2012. Laboratory Investigation of Compaction Characteristics and Performance of Warm Mix Asphalt

Containing Chemical Additives. Construction and Building Materials, 37: 239-247.

Shi, X., Y. Rew, E. Ivers, C.S. Shon, E.M Stenger, P. Park, 2017. Effects of thermally modified asphalt concrete on pavement temperature. International Journal of Pavement Engineering, 18(1): 1-13.

Sheng, Y., H. Li, P. Guo, G. Zhao, H. Chen, R. Xiong, 2017. Effect of Fibers on Mixture Design of Stone Matrix Asphalt. Appl. Sci., 7(3): 297.

Asi, I.M., 2007. Performance Evaluation of SUPERPAVE and Marshall Asphalt Mix Designs to Suite Jordan Climatic and Traffic Conditions. Construction and Building Material,. 21: 1732-1740.

ASTM, 2007. Standard Test Method for Bulk Specific Gravity and Density Of Compacted Bituminous Mixtures Using Coated Samples. ASTM International: D1188-07e1.

Dubois, V., C.D.L. Roche, O. Burban, 2010. Influence of The Compaction Process on The Air Void Homogeneity of Asphalt Mixtures Samples. Construction and Building Materials, 24(6): 885-897.

Khan, Z.A., A.A. Wahab, I.M. Asi, R. Ramadhan, 1998. Comparative Study of Asphalt Concrete Laboratory Compaction Methods to Simulate Field Compaction. Construction and Building Materials, 12(6-7): 373-84.

Airey, G.D., A.E. Hunter, A.C. Collop, 2008. The Effect of Asphalt Mixture Gradation and Compaction Energy on Aggregate Degradation. Construction and Building Materials, 22(5):972-980.

Hainin, M.R., N.I.M. Yusoff, M.K.I.M. Satar, E.R. Brown, 2013. The Effect Of Lift Thickness on Permeability and The Time Available for Compaction of Hot Mix Asphalt Pavement under Tropical Climate Condition. J. Construction and Building Materials, 48: $315-324$.

Ahmad, J., N.I.M. Yusoff, M.R. Hainin, M.Y.A. Rahman, M. Hossain, 2014. Investigation into Hot-Mix Asphalt Moisture-Induced Damage under Tropical Climatic Conditions. Construction and Building Materials, 50: 567-576.

García, A., J.N. Contreras, M.N. Partl, P. Schuetz, 2013. Uniformity and Mechanical Properties of Dense Asphalt Concrete with Steel Wool Fibers. Construction and Building Materials, 43: 107-117. 143.

Yoo, P.J., K.H. Kim, 2014. Thermo-plastic Fiber's Reinforcing Effect on Hot-mix Asphalt Concrete Mixture. Construction and Building Materials, 59: 136-

Huang, L.S., D.F. Lin, H.L. Luo and P.C. Lin, 2012. Effect of Field Compaction Mode on Asphalt Mixture Concrete with Basic Oxygen Furnace Slag. Construction and Building Materials, 34: 16-27.

Jiménez, F.P., A.H. Martínez, R. Miró, D.H. Barrera, L.A. Zamorano, 2014. Effect of Compaction Temperature and Procedure on The Design of Asphalt Mixtures Using Marshall and Gyratory Compactors, Construction and Building Materials, 65: 264-269. 